\title{
Sublimation Kinetics of Zirconium Tetrafluoride
}

\author{
C.J. Pretorius ${ }^{1, a^{*}}$, A.D. Pienaar ${ }^{1, b}$, P.L. Crouse ${ }^{2, c}$ and H.F. Niemand ${ }^{1, d}$ \\ ${ }^{1}$ The South African Nuclear Energy Corporation SOC Ltd. (Necsa), Pretoria, South Africa \\ ${ }^{2}$ Department of Chemical Engineering University of Pretoria, South Africa \\ a*Jakkie.Pretorius@necsa.co.za, ${ }^{\mathrm{b}}$ Andrew.Pienaar@necsa.co.za, ${ }^{\mathrm{c}}$ Philip.Crouse@up.ac.za, \\ ${ }^{\mathrm{d}}$ Hennie.Niemand2@gmail.com
}

Keywords: zirconium, hafnium, sublimation kinetics

\begin{abstract}
.
An important step of a new process being developed for the beneficiation of the mineral zircon $\left(\mathrm{Zr}(\mathrm{Hf}) \mathrm{SiO}_{4}\right)$ to produce nuclear grade zirconium $(\mathrm{Zr})$ metal, is the separation of the $\mathrm{Zr}$ from the hafnium (Hf). $\mathrm{Zr}$ ores typically contain between 1 and $3 \% \mathrm{Hf}$, whereas the use of $\mathrm{Zr}$ metal in the nuclear industry requires a Hf content $<100 \mathrm{ppm}$, owing to its relatively high neutron-capture cross section. The separation step is therefore key in the preparation of nuclear grade $\mathrm{Zr}$, which is considered to be very difficult due to the various similarities in their chemical properties.

The preparation of hafnium free zirconium relies on traditional wet separation systems, for example solvent extraction systems. In contrast to the traditional aqueous chloride systems, Necsa focusses on dry fluoride-based processes. Dry processes have the advantage of producing much less hazardous chemical waste.

In the work reported here, separation is achieved by sublimation/de-sublimation in the tetrafluoride form. The tetrafluoride is prepared by fluorination of plasma dissociated zircon (PDZ or $\left.\mathrm{Zr}(\mathrm{Hf}) \mathrm{O}_{2} \cdot \mathrm{SiO}_{2}\right)$ with ammonium bifluoride $(\mathrm{ABF})$. The separation involves the selective sublimation of the two tetrafluorides in an inert atmosphere under controlled conditions, and subsequent similarly selective desublimation.

An accurate estimation of the sublimation rates of both the zirconium tetrafluoride $\left(\mathrm{ZrF}_{4}\right)$ and hafnium tetrafluoride $\left(\mathrm{HfF}_{4}\right)$ as a function of temperature is required since this forms the basis of the development of a sublimation model to determine whether the concept under consideration is theoretically possible. The sublimation kinetics of $\mathrm{ZrF}_{4}$ is reported in this paper.
\end{abstract}

\section{Introduction}

Zirconium and hafnium in both metallic and compound states share a chemical similarity that is unequal by any other two homologous chemical elements in the periodic table [1]. This similarity results from their near identical atomic radii [2], and makes them difficult to separate. It is therefore quite a challenge to produce zirconium with hafnium levels of less than $100 \mathrm{ppm}$.

The literature describes several methods used for the separation of $\mathrm{Zr}$ and $\mathrm{Hf}$. Amongst these are fractional crystallization [3-6], solvent extraction (also liquid-liquid extraction or partitioning, [3,7-13] pertraction [14], ion exchange [3,15-17], extraction chromatography [18,19], selective reduction [5], extractive distillation in molten salts [20,21] and sublimation [22,23].

Information on sublimation purification of $\mathrm{ZrF}_{4}$ from non-volatile impurities practically only became available from early 1970 [24], after which its use as a purification technique became more apparent [25-32].

The AMI zirconium metal process developed by Necsa [33] involves the plasma dissociation of the mineral zircon to make it chemically reactive. The plasma dissociated zircon (PDZ) is fluorinated with ammonium bifluoride $(A B F)$ to produce $\mathrm{ZrF}_{4}$. Hafnium and zirconium are then separated and the zirconium compounds are reduced to the metal which can then be purified. The focus here is dry fluoride-based processes which have the advantage of producing much less hazardous chemical waste.

The sublimation kinetic parameters are required to obtain an estimated value for the sublimation rate and/or mass flux (mass transfer coefficient) of $\mathrm{ZrF}_{4}$, which is required to model the selective 
separation of $\mathrm{ZrF}_{4}$ and $\mathrm{HfF}_{4}$. Several reaction models are listed in the literature for the determination of solid state kinetics [34-36]. This paper describes the work that has been completed to develop a rate model which describes the sublimation mechanism of $\mathrm{ZrF}_{4}$. It provides a full set of kinetic parameters for the sublimation of $\mathrm{ZrF}_{4}$ making use of thermo-gravimetric analysis (TGA).

\section{Experimental}

Preparation of $\mathbf{Z r F}_{4}$. The $\mathrm{ZrF}_{4}$ material used for determining the kinetics were prepared by reacting $\mathrm{ABF}\left(\mathrm{NH}_{4} \mathrm{~F} \cdot \mathrm{HF}\right)$ and $\mathrm{PDZ}$ [37], in a nitrogen atmosphere with a tube furnace as heat source. X-Ray Diffraction (XRD) analysis indicated the major component to be $\mathrm{ZrF}_{4}$. Other peaks were that of zirconium oxy-fluorides, undissociated zircon and zirconium oxide.

A scanning electron microscope (SEM) image (Fig.1) indicated that the $\mathrm{ZrF}_{4}$ particles had formed agglomerates and that no definite geometry is apparent for the respective particles. This implies that the development of a reaction model is not trivial and several kinetic models need to be fitted to the data to determine the optimum.

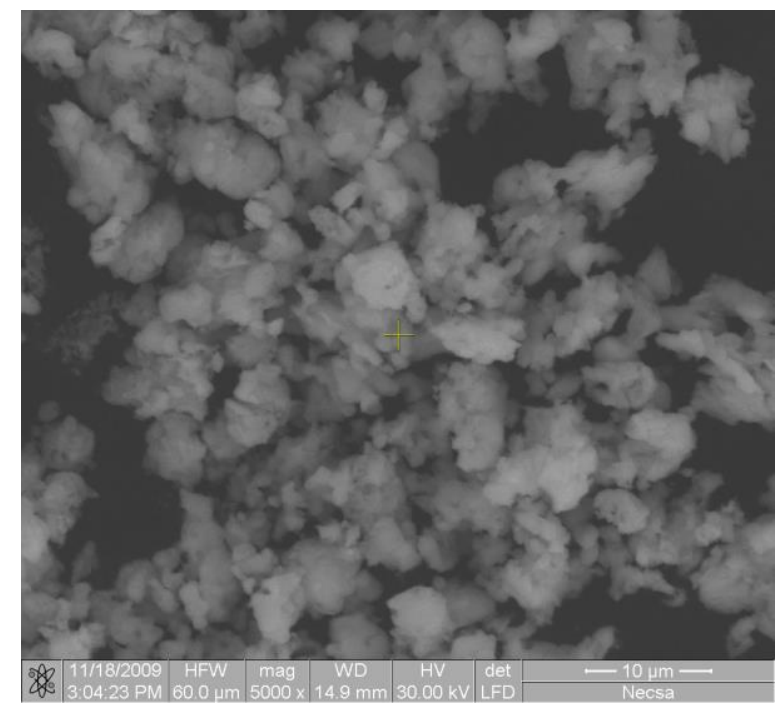

Figure 1: SEM image of $\mathrm{ZrF}_{4}$ particles

Thermogravimetric analysis. Non-isothermal sublimation data were collected on a TA Instruments QDT600 simultaneous thermogravimetric and differential scanning calorimetric (TG/DSC) analyser. All runs were completed using platinum crucibles and $100 \mathrm{~mL} \cdot \mathrm{min}^{-1} \mathrm{~N}_{2}$ purge at atmospheric pressure. Samples were transferred directly after synthesis to the TG in a sealed container filled with nitrogen. The samples were heated from ambient temperature to $950{ }^{\circ} \mathrm{C}$ at 2,5 , 10 and $15^{\circ} \mathrm{C} \cdot \mathrm{min}^{-1}$. The maximum sample size was $12 \mathrm{mg}$.

\section{Development of a reaction model}

The following equation is used to model the non-isothermal sublimation data obtained from nonisothermal thermogravimetric analysis [34-36]:

$$
\frac{d \alpha}{d T}=\frac{A e^{-E_{a} / R T}}{\beta} f(\alpha) .
$$

where $\alpha$ is defined by:

$$
\alpha=\frac{m_{\text {start }}-m_{\text {timet }}}{m_{\text {start }}-m_{\text {final }}} .
$$

The kinetic function $f(\alpha)$ is related to the reaction mechanism. $A$ is the pre-exponential factor, $E_{a}$ is the activation energy, $R$ is the universal gas constant, $T$ the temperature, and $\beta$ is the heating 
rate $\left(\beta=\frac{d T}{d t}\right) \cdot m_{\text {start }}$ is the mass $\mathrm{ZrF}_{4}$ to be sublimated, $m_{\text {time }}$ is the mass at time $t$ and $m_{\text {final }}$ is the final mass after sublimation. Rearranging and taking the natural logarithm of Eq. 1, one obtains the linear equation:

$$
\ln \left(\frac{\frac{d \alpha}{d T}}{f(\alpha)}\right)=\ln \left(\frac{A}{\beta}\right)-\frac{E_{a}}{R T},
$$

with slope $\frac{-E_{a}}{R}$ and intercept $\ln \left(\frac{A}{\beta}\right)$. If the correct form of $f(\alpha)$ is chosen the following criteria should be satisfied:

- A plot of $\ln \left(\frac{\frac{d \alpha}{d T}}{f(\alpha)}\right)$ vs $\frac{1}{T}$ will result in a straight line;

- The activation energy $\left(E_{a}\right)$ must be larger than the heat of sublimation;

- $\quad$ Both $E_{a}$ and $A$ must be independent of the heating rate.

Several reaction models $f(\alpha)$ have been listed and are described in the literature [34]. These functions are based on nucleating, geometrical contraction, diffusion and/or reaction-order models. Since the model for the sublimation of $\mathrm{ZrF}_{4}$ is unknown, the data were fitted to a number of the rate models listed in the literature.

\section{Results and Discussion}

Fig. 2 presents the non-isothermal mass loss data obtained by TGA for the sublimation of $\mathrm{ZrF}_{4}$ at heating rates of $2,5,10$ and $15{ }^{\circ} \mathrm{C} \cdot \mathrm{min}^{-1}$. Due to the definition of alpha, the presence of oxyfluorides and other impurities should not affect the sublimation data. Alpha values between 0.1 and 0.9 are shown. The geometrical contracting models for area (R2) and volume (R3) as well as the diffusion models (D1, D2, D3 and D4) allowed for straight line fits to the experimental data when substituted into Eq. 3. Table 1 lists the mathematical expressions of $f(\alpha)$ for the respective models.

Table 1: Solid state reaction models

\begin{tabular}{lcl}
\hline Model & Symbol & $\mathbf{f}(\boldsymbol{\alpha})=\mathbf{1} / \mathbf{k ~ d \alpha} / \mathbf{d t}$ \\
\hline Contracting area & R2 & $2(1-\alpha)^{1 / 2}$ \\
Contracting volume & R3 & $3(1-\alpha)^{2 / 3}$ \\
1-D Diffusion & D1 & $1 /(2 \alpha)$ \\
2-D Diffusion & D2 & $-[1 / \ln (1-\alpha)]$ \\
3-D Diffusion/Jander & D3 & {$\left[3(1-\alpha)^{2 / 3}\right] /\left[2\left(1-(1-\alpha)^{1 / 3}\right)\right]$} \\
Ginstling-Braunstein Diffusion & D4 & $2 /\left[2\left((1-\alpha)^{-1 / 3}-1\right)\right]$ \\
\hline
\end{tabular}

The second requirement for a correct model fit is for the sublimation activation energy to be larger than the enthalpy of sublimation, i.e. $240 \mathrm{~kJ}^{-\mathrm{mol}^{-1}}[38,39]$. The activation energies were determined from the slope of Eq. 3 for the respective heating rates. When fitting the geometrical contraction models (R2 and R3) the resultant activation energies are less than the required 240 $\mathrm{kJ} . \mathrm{mol}^{-1}$, with average values of 141.8 and $169 \mathrm{~kJ}^{-\mathrm{mol}^{-1}}$ respectively. All three of the diffusion models indicated activation energies between 280 and $360 \mathrm{~kJ} \cdot \mathrm{mol}^{-1}$, which is more than the sublimation enthalpy mentioned above.

Except in the cases of a few reversible reactions, or where large amounts of heat is consumed or evolved, solid state reaction are not usually controlled by mass-transfer (diffusion) [33]. It is thus surprising that the sublimation of $\mathrm{ZrF}_{4}$ appears to be diffusion controlled. Diffusion may be a result 
of the agglomerated particles, or diffusion of the product into the carrier gas. Further insight into the diffusion mechanism may be gained by determining the porosity of the sample, but this is beyond the scope of the current work.

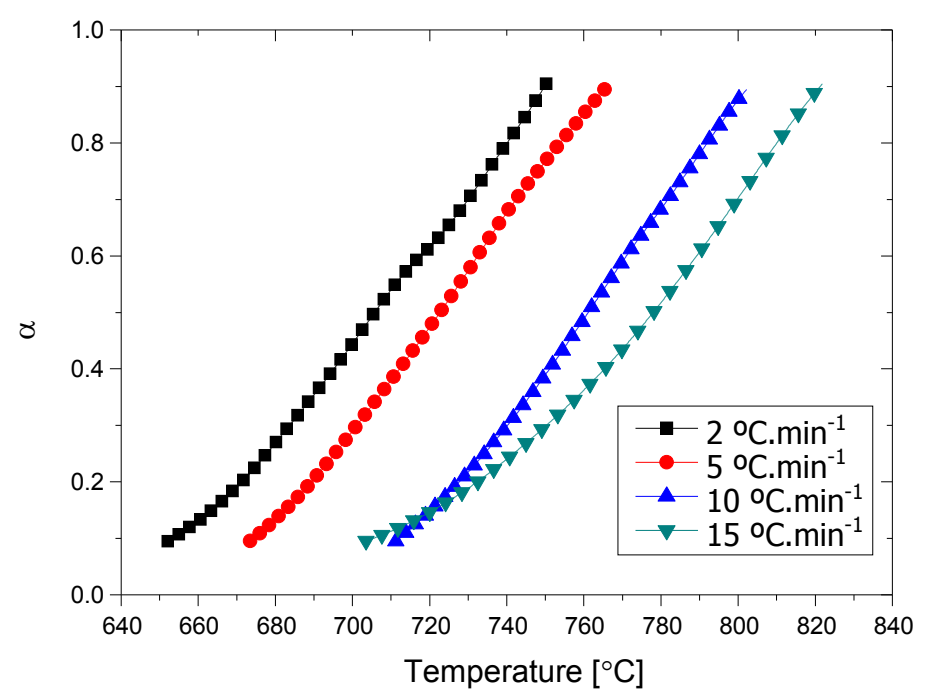

Figure 2: TGA results for $\mathrm{ZrF}_{4}$ sublimated at heating rates of 2, 5, 10, and $15{ }^{\circ} \mathrm{C} \cdot \mathrm{min}^{-1}$

All three diffusion models listed in Table 1 requires consideration. It was shown that the D3 model is oversimplified and holds only at low conversion values [34]. Since the less simplified D4 model also considers diffusion in three dimensions, the decision was made to discard the D3 threedimensional model for the evaluation of the $\mathrm{ZrF}_{4}$ sublimation data.

Plots of $\ln \left(\frac{\frac{d \alpha}{d T}}{f(\alpha)}\right)$ vs. $\frac{1}{T}$ for the D2 and D4 diffusion models are given in Fig. 3 and Fig. 4, respectively.

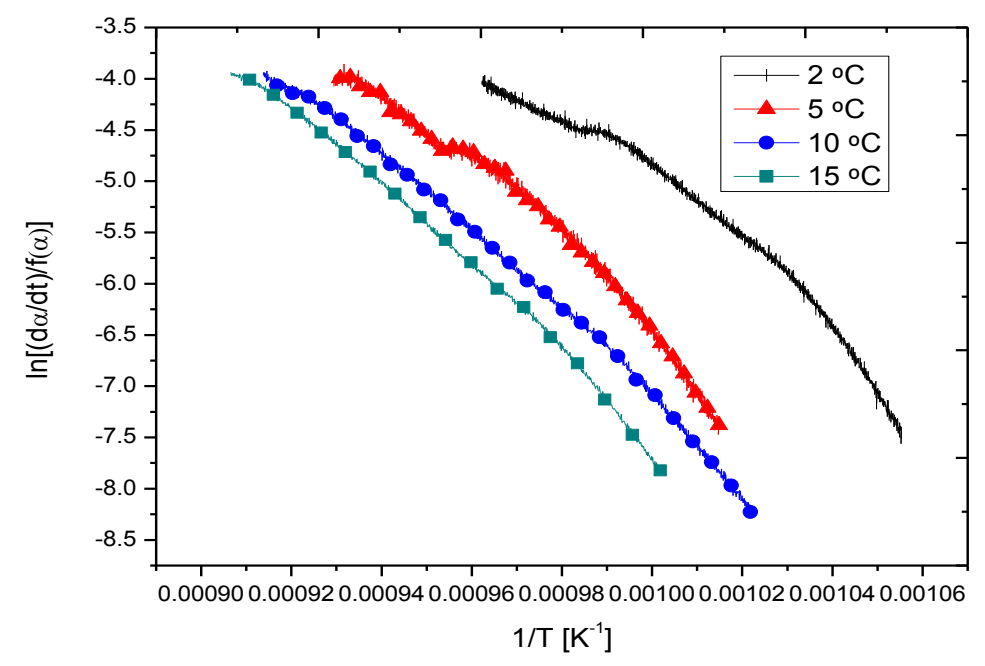

Figure 3: Plot of $\ln \left(\frac{\frac{d \alpha}{d T}}{f(\alpha)}\right)$ vs $\frac{1}{T}$ for the D2 diffusion model 


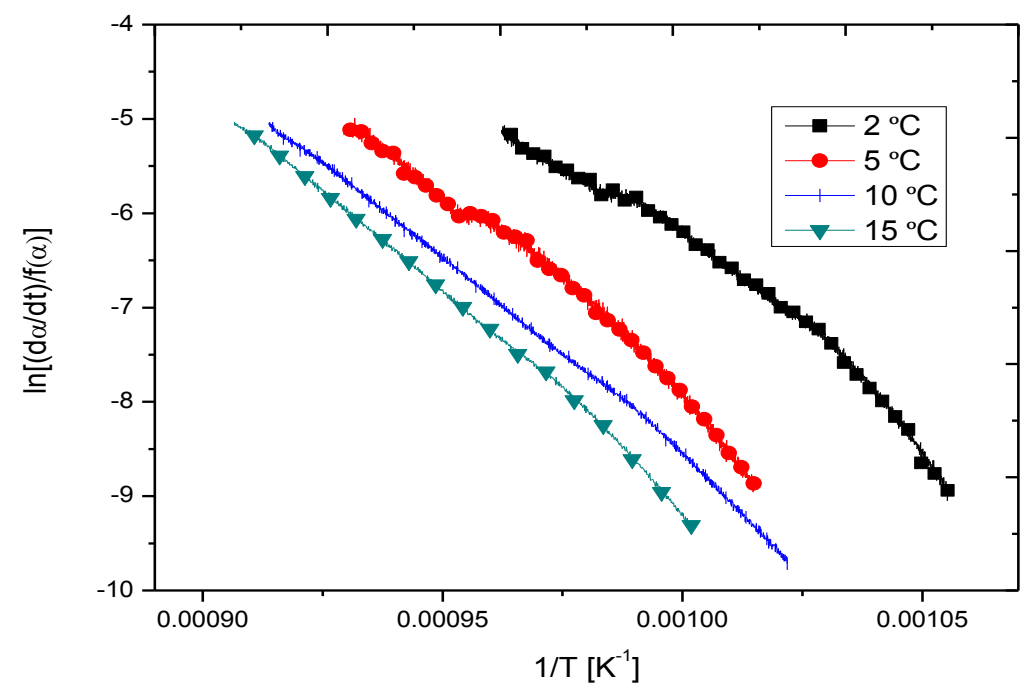

Figure 4: Plot of $\ln \left(\frac{\frac{d \alpha}{d T}}{f(\alpha)}\right)$ vs $\frac{1}{T}$ for the D4 diffusion model

Visual inspection of these figures, which is confirmed by the correlation coefficients, shows that a linear fit is better for the D4 model than the $\mathrm{D} 2$ model. The respective $\mathrm{R}^{2}$ values are listed in Table 2, with the corresponding kinetic parameters in Table 3.

Table 2: Respective $\mathrm{R}^{2}$ values for $\mathrm{D} 2$ and $\mathrm{D} 4$

\begin{tabular}{ccc}
\hline $\begin{array}{c}\text { Heating rate } \\
{\left[{ }^{\circ} \mathbf{C} \text { min }^{-1}\right]}\end{array}$ & $\begin{array}{c}\text { D2 model } \mathbf{R}^{\mathbf{2}} \\
\text { values }\end{array}$ & $\begin{array}{c}\text { D4 model } \mathbf{R}^{2} \\
\text { values }\end{array}$ \\
\hline 2 & 0.9557 & 0.9729 \\
5 & 0.9719 & 0.9833 \\
10 & 0.9939 & 0.9976 \\
15 & 0.9935 & 0.9974 \\
\hline
\end{tabular}

Table 3: Activation energies and pre-exponential constants obtained from the D2 and D4 models for the sublimation of $\mathrm{ZrF}_{4}$.

\begin{tabular}{|c|c|c|c|c|}
\hline \multirow{2}{*}{$\begin{array}{c}\text { Heating rate } \\
(\boldsymbol{\beta}) \\
{\left[{ }^{\circ} \mathrm{C} \cdot \mathrm{min}^{-1}\right]}\end{array}$} & \multicolumn{2}{|c|}{ D2 model } & \multicolumn{2}{|c|}{ D4 model } \\
\hline & $\boldsymbol{A}$ & $\begin{array}{c}E_{a} \\
{\left[\mathrm{~kJ} \cdot \mathrm{mol}^{-1}\right]}\end{array}$ & $A$ & $\begin{array}{c}E_{a} \\
{\left[\mathrm{kJJ} \mathrm{mol}^{-1}\right]}\end{array}$ \\
\hline 2 & $6.85 \times 10^{12}$ & 282 & $7.28 \times 10^{13}$ & 312 \\
\hline 5 & $5.45 \times 10^{14}$ & 322 & $6.15 \times 10^{15}$ & 355 \\
\hline 10 & $7.08 \times 10^{14}$ & 324 & $2.84 \times 10^{15}$ & 348 \\
\hline 15 & $2.54 \times 10^{15}$ & 335 & $1.50 \times 10^{16}$ & 362 \\
\hline Average & $9.50 \times 10^{14}$ & 316 & $6.00 \times 10^{15}$ & 344 \\
\hline
\end{tabular}

Values obtained for both the activation energies and pre-exponential constants show that the D2 and D4 models deviate from linearity at the $2{ }^{\circ} \mathrm{C} \cdot \mathrm{min}^{-1}$ heating rate when compared to the other heating rates. Limited sample thermal conductivity or thermal effects due to self-heating/cooling may cause deviations in the sample temperatures [36]. According to Vyazovkin, the difference in sample and reference temperature becomes larger at faster heating rates, which may cause an error of $10-20 \%$ in $E_{a}$ and $\ln A$ between the high and low heating rates. Typical approaches to minimize these effects may be to decrease the sample size and heating rate. 
The error is calculated by dividing the value of $E_{a}$ and/or $\ln A$ by the average value obtained of the respective heating rates. The error in $\ln A$ between the 2 and $15{ }^{\circ} \mathrm{C} . \mathrm{min}^{-1}$ heating rates for the D2 and D4 models are 18 and $15 \%$ respectively, and the $E_{a}$ errors for the two models are 17 and $14 \%$ respectively. Using the work by Vyazovkins theory as guideline, this suggest that the sample masses and/or heating rates used in determining the TG data may have been higher than what is ideal.

Selection of the model also depends on the geometry of the particles. The D2 model is derived for cylindrical particles and the D4 model for spherical particles. Since the SEM image was not indicative of any definite particle geometry, no distinction between these two models can be made.

Approximate values for the pre-exponential constant and activation energy have therefore been calculated from both models. The average values obtained are listed in Table 3.

Sublimation of $\mathrm{ZrF}_{4}$ under vacuum described in literature is based on first order isothermal kinetics, with a value for the apparent activation energy of $0.42 \mathrm{~kJ} \mathrm{~mol}^{-1}$. According to Solov'ev and Malyutina, this is indicative that the process is realized in the diffusion region. The optimal temperature were reported in the range $820-870{ }^{\circ} \mathrm{C}$ with a pressure in the range 3-4 $\mathrm{Pa}$ [24].

\section{Conclusions}

A D2 and/or D4 diffusion model sufficiently describes the mechanism for the sublimation of $\mathrm{ZrF}_{4}$. Distinct differences were detected between the high and low heating rates, which is indicative of either too large sample masses used, and/or too high heating rates.

\section{Recommendations}

It is recommended to determine the extent of porosity of the $\mathrm{ZrF}_{4}$ starting material. It is further recommended to do several TGA experiments whereby runs are performed on samples with markedly different masses, making sure that the data give rise to kinetic curves that can be superimposed [36]. This is required to test the sample requirements for accurate kinetic evaluations with TGA.

Furthermore, it is also recommended to determine the sublimation kinetics of $\mathrm{HfF}_{4}$. These results will then indicate any kinetic similarities between the two metal fluorides.

\section{References}

[1] X. J. Yang, A. G. Fane, C. Pin, Separation of zirconium and hafnium using hollow fibres: Part I. Supported liquid membranes, Chem. Eng. J. 88 (2002) 37-44.

[2] M. Smolik, A. Jakóbik-Kolon, M. Porański, Separation of zirconium and hafnium using Diphonix ${ }^{\circledR}$ chelating ion-exchange resin, Hydrom. 9 (2009) 350-353.

[3] M. Benedict, T. H. Pigford, H. W. Levi, Nuclear Chemical Engineering. McGraw-Hill, New York, 1981, pp. 333-341.

[4] D. J. Branken, G. Lachman, H.M. Krieg, O.S.L. Bruinsma, Influence of KF and HF on the selectivity of $\mathrm{Zr}$ and $\mathrm{Hf}$ Separation by Fractional Crystallization of $\mathrm{K}_{2} \mathrm{Zr}(\mathrm{Hf}) \mathrm{F}_{6}$, Ind. Amp Eng. Chem. Res. 49 (2010) 797-808.

[5] H. Ishizuka, Process for refining zirconium tetrachloride containing hafnium tetrachloride, US Patent number: 385,647,724 (1974).

[6] K. Reuter, G. Passing, S. Kirchmeyer, Process for separating zirconium and hafnium, US Patent number: 763,539,622 (2009).

[7] Z. Xu, L. Wang, Y. Wu, R. Chi, L. Zhang, M. Wu, Solvent extraction of hafnium from thiocyanic acid medium in DIBK-TBP mixed system, Trans. Nonferrous Met. Soc. China. 22 (2012) 1760-1765. 
[8] R. Banda, H. Y. Lee, M. S. Lee, Separation of $\mathrm{Zr}$ from $\mathrm{Hf}$ in hydrochloric acid solution using amine-based extractants, Ind. Eng. Chem. Res. 51 (2012) 9652-9660.

[9] N. V. Deorkar, S. M. Khopkar, Liquid-liquid extraction of zirconium from hafnium and other elements with dicyclohexyl-18-crown-6, Anal. Chim. Acta. 245 (1991) 27-33.

[10] A. E. P. Brown, T. V. Healy, Separation of zirconium from hafnium in nitric acid solutions by solvent extraction using dibutyl butylphosphonate: Part 1. Chemistry of the separation, Hydrom. 3 (1978) 265-274.

[11] M. Taghizadeh, R. Ghasemzadeh, S. N. Ashrafizadeh, K. Saberyan, M. G. Maragheh, Determination of optimum process conditions for the extraction and separation of zirconium and hafnium by solvent extraction, Hydrom. 90 (2008) 115-120.

[12] M. Taghizadeh, M. Ghanadi, E. Zolfonoun, Separation of zirconium and hafnium by solvent extraction using mixture of TBP and Cyanex 923, J. Nucl. Mater. 412 (2011) 334-337.

[13] L. E. Sarbeck, D. R. Lee, L. J. Jacoby, J. C. Haygarth, C. T. Goodwin, W. A. Crocker, Zirconium-hafnium separation process, US Patent number 517,687,805 (1993).

[14] X. J. Yang, A. G. Fane, C. Pin, Separation of zirconium and hafnium using hollow fibres: Part I. Supported liquid membranes, Chem. Eng. J. 88 (2002) 37-44.

[15] C. H. Byers, W. G. Sisson, T. S. Snyder, R. J. Beleski, T. L. Francis, U. P. Nayak, Zirconium and hafnium separation in chloride solutions using continuous ion exchange chromatography, US Patent number: 576,289,009 (1998).

[16] J. M. Begovich, W. G. Sisson, Continuous ion exchange separation of zirconium and hafnium using an annular chromatograph, Hydrom. 10 (1983) 11-20.

[17] F. J. Hurst, Separation of hafnium from zirconium in sulphuric acid solutions using pressurized ion exchange, Hydrom. 10 (1983) 1-10.

[18] X. J. Yang, C. Pin, A. G. Fane, Separation of hafnium from zirconium by extraction chromatography with liquid anionic exchangers, J. Chromatogr. Sci. 37 (1999) 171-179.

[19] K. T. Qiuquan Wang, Separation of zirconium(IV) and hafnium(IV) by extraction chromatography using di(1-methylheptyl) methylphosphonate as a stationary phase, Anal. Sci. 13 (1997) 27-31.

[20] L. Delons, S. Lagarde, A. Favre-reguillon, S. Pellet-Rostaing, M. Lemaire, L. Poriel, Process for the separation and purification of hafnium and zirconium, US Patent number: 770,896,204 (2010).

[21] D. F. McLaughlin, R. A. Stoltz, Molten salt extractive distillation process for zirconiumhafnium separation, US Patent number: 487447517 (1989).

[22] O. S. Monnahela, W. G. Augustyn, J. T. Nel, C. J. Pretorius, J. B. Wagener, The Vacuum Sublimation Separation of Zirconium and Hafnium Tetrafluoride, PMDN Conference, Cape Town, 2013.

[23] A. I. Solov'ev, V. M. Malyutina, Production of metallic zirconium tetrafluoride purified from hafnium to reactor purity, Russ. J. Non-Ferr. Met. 43 (2002) 14-18.

[24] A. I. Solov'ev, V. M. Malyutina, Metallurgy of less-common and precious metals. Production of metallurgical semiproduct from zircon concentrate for use in production of plastic metallic zirconium, Russ. J. Non-Ferr. Met. 43 (2002) 9-13.

[25] J. Withers, A. J. Woytek, J. T. Lileck, Process for the production of high purity zirconium tetrafluoride and other fluorides," US Patent number: 4983373 (1991). 
[26] M. L. Kotsar', V. B. Bateev, P. B. Baskov, V. V. Sakharov, V. D. Fedorov, V. V. Shatalov, Preparation of high-purity $\mathrm{ZrF}_{4}$ and $\mathrm{HfF}_{4}$ for optical fibres and radiation-resistant glasses, Inorg. Mater. 37 (2001) 1085-1091.

[27] G. Dai, J. Huang, J. Cheng, C. Zhang, G. Dong, K. Wang, A new preparation route for high purity $\mathrm{ZrF}_{4}$, J. Non-Cryst. Solids, 140 (1992) 229-232.

[28] K. Fujiura, Y. Ohishi, S. Sakaguchi, Synthesis of high-purity $\mathrm{ZrF}_{4}$ by chemical vapordeposition, Yogyo-Kyokai-Shi. 95 (1987) 86-88.

[29] D. R. MacFarlane, P. J. Newman, A. Voelkel, Methods of purification of zirconium tetrafluoride for fluorozirconate glass, J. Am. Chem. Soc. 85 (2002) 1610-1612.

[30] R. C. Pastor, M. Robinson, Method for preparing ultra-pure zirconium and hafnium tetrafluorides, US Patent number: US 457,8252 A25 (1986).

[31] R. C. Folweiler, Chemical vapor purification of fluorides, US Patent number: US 465,2438 A24 (1987).

[32] L. J. Abate, H. A. Wilhelm, Sublimation of zirconium tetrafluoride, United States Atomic Energy Commission, Ames Laboratory, ISC-151 (1951).

[33] J.T. Nel, W.L. Retief, J.L. Havenga, W. du Plessis, J.P. le Roux, Treatment of chemical feedstocks. WO2013054282 A1 (2013)

[34] A. Khawam, D. R. Flanagan, Solid-state kinetic models: basics and mathematical fundamentals, J. Phys. Chem. B. (2006) 17315-17328.

[35] J. H. Shin, M. S. Choi, D. J. Min, J. H. Park, Isothermal and non-isothermal sublimation kinetics of zirconium tetrachloride $\left(\mathrm{ZrCl}_{4}\right)$ for producing nuclear grade $\mathrm{Zr}$, Mater. Chem. Phys. 143 (2014) 1075-1081.

[36] S. Vyazovkin, A. K. Burnham, J. M. Criado, L. A. Pérez-Maqueda, C. Popescu, N.

Sbirrazzuoli, ICTAC Kinetics Committee recommendations for performing kinetic computations on thermal analysis data, Thermochim. Acta,. 520 (2011) 1-19.

[37] J.T. Nel, W. du Plessis, P.L. Crouse, W.L. Retief, Treatment of zirconia-based material with ammonium bi-fluoride. WO2011013085 A1 (2011).

[38] J. S. Chickos, W. E. Acree, Jr., Enthalpies of Sublimation of Organic and Organometallic Compounds. 1910-2001, J. Phys. Chem. Ref. Data. 31 (2002).

[39] P. L. Brown, E. Curti, and B. Grambow, Chemical Thermodynamics of Zirconium, OECD Nuclear Energy Agency, Data Bank, Issy-les-Moulineaux (France). 